\title{
IgE-dependent reactivity of canine sera from three regions of Poland
}

\author{
BARTOSZ JANIA, MARTA DOPIERAŁA*, EWA WÓJCIK*, \\ KATARZYNA RYMUZA**, KATARZYNA ANDRASZEK*
}

\author{
LAB-WET Laboratory of Veterinary Diagnostic, ul. Wita Stwosza 30, 02-661 Warszawa \\ *Institute of Animal Science and Fisheries, **Institute of Agriculture and Horticulture, \\ Siedlce University of Natural Sciences and Humanities, ul. B. Prusa 14, 08-110 Siedlce, Poland
}

\section{Jania B., Dopierała M., Wójcik E., Rymuza K., Andraszek K. IgE-dependent reactivity of canine sera from three regions of Poland}

Summary

Allergies in dogs have become a relatively frequent topic of discussion in veterinary surgeries. Many dogs, both purebred and of mixed breeds, are diagnosed for allergies. Allergies have many causes, from genetic predisposition to the environmental conditions in which the animal lives. Allergies in dogs are troublesome because they can lead to serious health complications when diagnosed late or left untreated. The results of the study support the hypothesis that the percentage of allergies to individual allergens varied by region (Tab. 4). Differences were observed in the case of Dermatophagoides pteronyssinus and Dermatophagoides farinae house dust mites, Acarus siro, and Tyrophagus. The remaining allergens caused allergic reactions in similar percentages of dogs from northern, central and southern Poland.

Keywords: dog, allergy, allergen

Allergies affect not only people, but also animals, including dogs. There are many factors and substances in our environment that can cause allergic reactions. An allergy is the body's immune response to foreign substances, i.e. allergens. It is a hypersensitivity based on immune mechanisms (16, 22-26). A clinical inflammatory response then occurs, which is correlated with an elevated concentration of class $E$ antibodies (6).

If allergies caused by environmental factors are suspected, it is necessary to perform provocation tests (exposure to the suspected allergen on the skin or in food) or in vitro tests (determination of total $\operatorname{IgE}$ concentration or of IgE subclasses against specific allergens) (2). It should be noted, however, that this type of testing should take place after other etiological agents of dermatosis have been eliminated (e.g. skin parasites or fungal infections). Many asymptomatic dogs test positive in both types of allergy tests (19). However, these tests are very useful in animals diagnosed with atopic dermatitis, because they make it possible to detect and control environmental factors (allergic reactions to mites, fleas, pollen, food products, etc.) that aggravate the clinical condition (2).

With the increase in veterinary care standards in the mid- $19^{\text {th }}$ century, skin allergy tests were routinely in- troduced in small animal veterinary diagnostics $(3,13)$. The tendency for allergy is related to breed. Therefore a genetic (breed) database of susceptibility to specific allergens in dogs has been created, and has recently been confirmed by genomic microarray analysis (17, $21,27)$.

In dog allergology, house dust mites (Dermatophagoides farinae and Dermatophagoides pteronyssinus) are considered the most important allergens. The clinical significance of these microorganisms is further documented by a number of studies confirming the presence of mites and their antigens in the living environment of dogs and on their skin and fur, as well as by clinical symptoms and T-cell responses after exposure to dust mite antigens in sensitized dogs $(2,11)$. However, skin reactivity, as well as a serum concentration of $\operatorname{IgE}$ specific to dust mites, has been shown to occur in a large number of non-symptomatic dogs, which indicates that sensitization is not always associated with clinical symptoms. In some geographic areas, including the United Kingdom, D. pteronyssinus is the dominant mite in the environment, while in other areas $D$. farinae is more common $(8,17)$. Another group of microorganisms causing allergies in dogs are storage mites (Tyrophagus putrescentiae, Lepidogly- 
phus destructor and Acarus siro) $(6,26)$. Mites have been found in the living environment of dogs, as well as in dog food. The amount of contaminants in dog food seems to depend on environmental conditions, including temperature and humidity, as well as on the packaging material and how long it has been opened (4). High cross-reactivity has been observed between antigens of house dust mites and storage mites. Exposure to storage mites leads to clinical symptoms in Beagles that are allergic to house dust mites (14). This further complicates interpretation of the clinical significance of sensitivity to storage mites and confirms breed-dependent susceptibility to allergens. The number of dogs allergic to grass pollen has been rising (from $14.4 \%$ in 1999 and 2002 to $27.7 \%$ in 2007 and 2010). Over $80 \%$ of 262 tests were positive for at least one allergen, and $21 \%$ for at least one pollen allergen. This trend is similar to that observed in humans (20).

Flea allergy is another common allergy in dogs. In intradermal studies, positive reactions to fleas are more common than reactions to other insects. Antibodies against flea antigens were isolated from the serum of dogs many years ago. IgE antibodies against flea antigens develop in over half of dogs in environments with fleas. This antigen is considered to be a major allergen in dogs (10).

Insect allergies other than flea allergies are relatively rare in dogs. Local and sometimes systemic anaphylactoid and anaphylactic reactions have been noted after stings by hymenopterans. However, the frequency of anaphylactic reactions to stings by bees or vespids (wasps and hornets) is unknown in companion animals, and it is not always known whether these reactions are immune-mediated or due to intoxication. There is limited published information on hypersensitive reactions to biting insects such as black flies, mosquitoes, deer flies, horse flies, red ants and black ants. Pruritic skin lesions are usually located in areas of the body where the hair coat is thin, although there are specific regional areas of predisposition, such as the ears and the area behind the ears (17).

In contrast to environmental allergens, studies evaluating food allergens in veterinary medicine are rare. Studies of allergic reactions in the digestive system following elimination diets are very difficult and not double-blind. Many studies have shown that skin and serum tests for food allergens are unreliable $(9,17)$.

Allergies in dogs are troublesome because they can lead to serious health complications when diagnosed late or left untreated. For example, allergic reactions that cause itchy skin lesions can result in open wounds due to the dog's constant scratching. Therefore, it is important to consult a veterinarian about any worrying skin reactions in a dog as soon as possible.

The overall number of pets, and thus the number of animals diagnosed with allergies, is constantly rising, as is the awareness of veterinary allergies and interest in them. Unlike murine models, dogs and cats kept as pets are generally exposed to the same environmental influences as humans, and therefore are much better model animals for research on human allergies.

The aim of the study was to determine the frequency of different types of allergies in dogs from three regions of Poland.

\section{Material and methods}

The research covered canine patients of veterinary clinics and surgeries in northern Poland (Gdańsk and vicinity), central Poland (Warsaw and vicinity), and southern Poland (Kraków, Katowice and Nowy Sącz and vicinity). The dogs showed no clinical symptoms of atopic disease. The analyses were carried out at the facilities of the LAB-WET Veterinary Diagnostic Laboratory in Gdańsk, Kraków and Warsaw. The research material was classified according to the cities where the analyses were carried out. The number of animals in each group, broken down by sex, is given in Table 1.

Tab. 1. Number of dogs tested according to place of residence

\begin{tabular}{|l|c|c|c|}
\hline \multirow{2}{*}{ Area of Poland } & \multicolumn{3}{c|}{ Number of individuals tested } \\
& $\delta$ & $q$ & Total $(\widehat{\jmath}+q)$ \\
\hline Northern Poland & 14 & 13 & 27 \\
Central Poland & 12 & 17 & 29 \\
Southern Poland & 62 & 67 & 129 \\
Total & 88 & 97 & 185 \\
\hline
\end{tabular}

A Polycheck allergy panel was used in the research, with 15 individual allergens and 5 mixtures (pollen of grasses, trees and weeds, house dust mites, storage mites, moulds, Malassezia, and fleas).

Immunoglobulin E (IgE) antibodies specific for the following antigens were determined in the peripheral blood serum of the animals: $D$. farinae - house dust mites of the species Dermatophagoides farinae, D. pteronyssinus - house dust mites of the species Dermatophagoides pteronyssinus, Malassezia - fungi of the genus Malassezia, Lepidoglyphus - storage mites, Aspergillus/Penicillium - fungi of the genera Aspergillus and Penicillium, Alternaria/Cladosporium - fungi of the genera Alternaria and Cladosporium, Ragweed, Birch/Alder/Hazel - plant pollen, Plane tree/Willow/Poplar - plant pollen, Parietaria - upright pellitory - plant pollen, Rye - pollen, Mixed grasses - pollen, Nettle - pollen, Goosefoot - pollen, Ribwort plantain - pollen, Mugwort - pollen, Sorrel - pollen, Acarus siro - flour mites, Tyrophagus - mites Tyrophagus putrescentiae, Fleas - toxins.

A computer with a scanner and dedicated software were used to calculate the results. Cassettes placed on the flat scanner were read, and the program analysed data from the image. The program's conversion formula gives the number of IgE antibodies specific for a given allergen in kilounits per
Tab. 2. Levels of allergic reactions

\begin{tabular}{|c|c|}
\hline Concentration of $\lg E(\mathrm{kU} / \mathrm{l})$ & Level \\
\hline$<0.5$ & 0 \\
$(0.5-2.0)$ & 1 \\
$(2.0-20)$ & 2 \\
$\geq 20$ & $3-4$ \\
\hline
\end{tabular}


litre $(\mathrm{kU} / \mathrm{l})$. The IgE concentration levels are presented in Table 2.

Because the sample sizes varied between regions, all results were converted to percentages.

As the percentage distribution of results was in the range of 0 to $20 \%$, the data were subjected to the arcsine transformation for statistical analyses. Two-way analysis of variance (ANOVA) was used to analyse differences in the incidence of individual allergens (relative to their total number) between regions. Two-way ANOVA was also used to analyse differences between regions in terms of the incidence of allergies in the dogs. The Tukey test at $p \leq 0.05$ was used to compare means. The chi-square test was used to analyse relationships between allergen classes and region in terms of the frequency of positive reactions.

\section{Results and discussion}

Figure 1 presents the frequency of allergies to individual allergens in the entire study population of 185 dogs. The factors most responsible for the occurrence of allergies in dogs were house dust mites and mites of the family Acaridae. The frequency of reactions to these factors ranged from almost $50 \%$ to over $70 \%$. The second group of allergens, in terms of the frequency of inducing a reaction, comprised storage mites, rye, fleas, pollen from birch, alder, hazel, grasses and ribwort plantain, and fungi of the genus Malassezia. The frequency of allergy to these factors varied from $42 \%$ to $26 \%$. About a $10 \%$ frequency of positive reactions in the dogs was found for ragweed, sorrel, mugworts, goosefoot, and pollen from plane trees, willows and poplars. The least sensitizing factors were fungi of the genera Alternaria, Cladosporium, Aspergillus and Penicillium, and upright pellitory ( $3-4 \%$ frequency).

Table 3 presents the frequency of allergy to individual allergens in comparison to all those analysed. Statistical analysis showed no differences between regions. The table shows that the most common allergen, recorded in as many as 135 cases, was the house dust mite Dermatophagoides pteronyssinus. The frequency of its occurrence among all allergens was $13.4 \%$. A positive reaction to this allergen was most frequent in the group of dogs from southern Poland - 13.4\% of all positive reactions. In dogs from northern and central Poland, positive reactions were

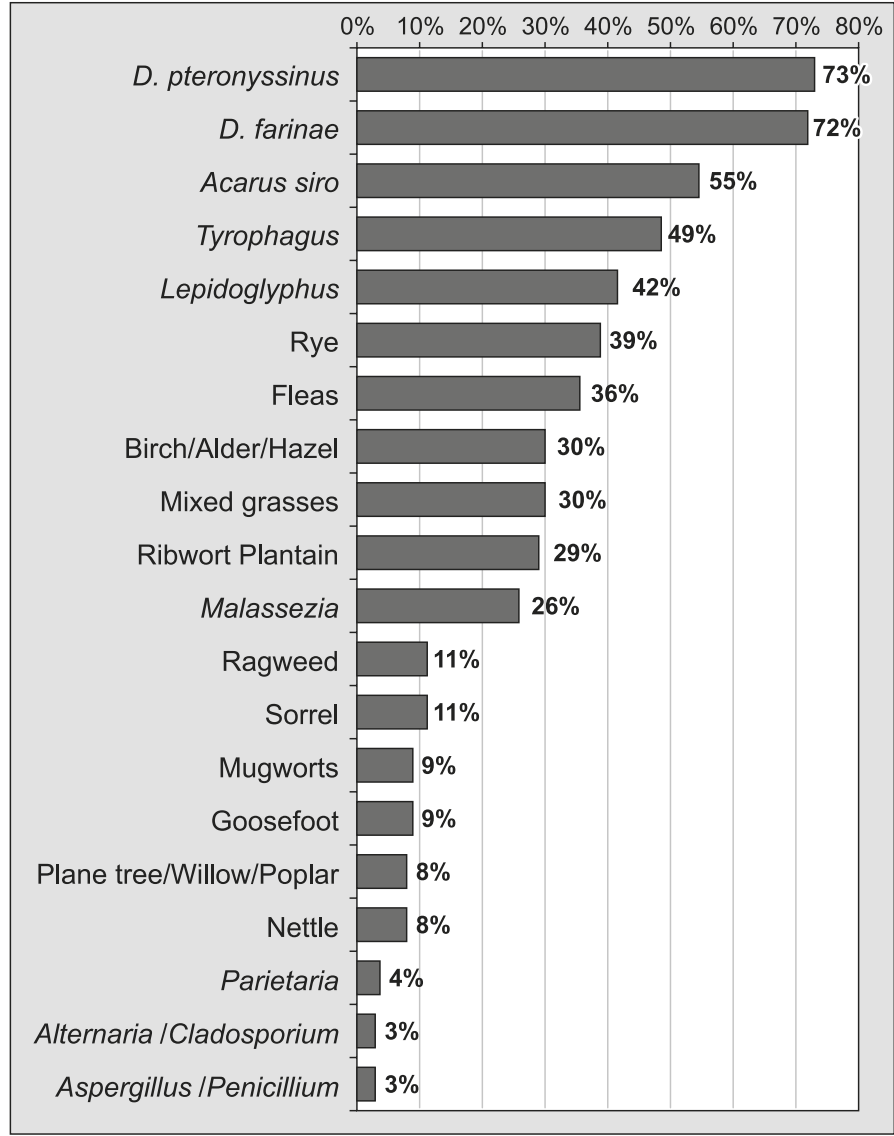

Fig. 1. Frequency of allergies to specific allergens

Tab. 3. Frequency of allergies to individual allergens in the dogs tested

\begin{tabular}{|c|c|c|c|c|c|c|c|c|}
\hline \multirow{2}{*}{ Allergen } & \multicolumn{2}{|c|}{ Northern Poland } & \multicolumn{2}{|c|}{ Central Poland } & \multicolumn{2}{|c|}{ Southern Poland } & \multicolumn{2}{|c|}{ Total } \\
\hline & Number & $\%$ & Number & $\%$ & Number & $\%$ & Number & $\%$ \\
\hline D. farinae & 22 & $12.8^{\mathrm{a}}$ & 17 & $15.5^{\mathrm{a}}$ & 94 & $12.9^{\mathrm{a}}$ & 133 & 13.2 \\
\hline D. pteronyssinus & 21 & $12.2^{\mathrm{a}}$ & 16 & $14.5^{\mathrm{a}}$ & 98 & $13.4^{\mathrm{a}}$ & 135 & 13.4 \\
\hline Malassezia & 8 & $4.7^{\mathrm{a}}$ & 5 & $4.5^{\mathrm{a}}$ & 35 & $4.8^{\mathrm{a}}$ & 48 & 4.7 \\
\hline Lepidoglyphus & 13 & $7.6^{\mathrm{a}}$ & 6 & $5.5^{\mathrm{a}}$ & 58 & $8.0^{\mathrm{a}}$ & 77 & 7.6 \\
\hline Aspergillus/Penicillium & 0 & $0.0^{\mathrm{a}}$ & 2 & $1.8^{\mathrm{a}}$ & 3 & 0.4 & 5 & 0.5 \\
\hline Alternaria/Cladosporium & 0 & $0.0^{\mathrm{a}}$ & 0 & $0.0^{\mathrm{a}}$ & 6 & $0.8^{\mathrm{a}}$ & 6 & 0.6 \\
\hline Ragweed & 3 & $1.7^{\mathrm{a}}$ & 3 & $2.7^{\mathrm{a}}$ & 15 & $2.1^{\mathrm{a}}$ & 21 & 2.1 \\
\hline Birch/Alder/Hazel & 11 & $6.4^{\mathrm{a}}$ & 7 & $6.4^{\mathrm{a}}$ & 38 & $5.2^{\mathrm{a}}$ & 56 & 5.5 \\
\hline Plane tree/Willow/Poplar & 2 & $1.2^{\mathrm{a}}$ & 1 & $0.9^{a}$ & 12 & $1.6^{\mathrm{a}}$ & 15 & 1.5 \\
\hline Parietaria & 0 & $0.0^{\mathrm{a}}$ & 0 & $0.0^{\mathrm{a}}$ & 7 & $1.0^{\mathrm{a}}$ & 7 & 0.7 \\
\hline Rye & 13 & $7.6^{\mathrm{a}}$ & 6 & $5.5^{\mathrm{a}}$ & 53 & 7.3 & 72 & 7.1 \\
\hline Mixed grasses & 10 & $5.8^{\mathrm{a}}$ & 5 & $4.5^{\mathrm{a}}$ & 41 & $5.6^{\mathrm{a}}$ & 56 & 5.5 \\
\hline Nettle & 2 & $1.2^{\mathrm{a}}$ & 3 & $2.7^{\mathrm{a}}$ & 10 & $1.4^{\mathrm{a}}$ & 15 & 1.5 \\
\hline Goosefoot & 3 & $1.7^{\mathrm{a}}$ & 2 & $1.8^{\mathrm{a}}$ & 11 & $1.5^{\mathrm{a}}$ & 16 & 1.6 \\
\hline Ribwort Plantain & 12 & $7.0^{\mathrm{a}}$ & 5 & $4.5^{\mathrm{a}}$ & 37 & $5.1^{\mathrm{a}}$ & 54 & 5.3 \\
\hline Mugworts & 3 & $1.7^{\mathrm{a}}$ & 2 & $1.8^{\mathrm{a}}$ & 12 & $1.6^{\mathrm{a}}$ & 17 & 1.7 \\
\hline Sorrel & 3 & $1.7^{\mathrm{a}}$ & 3 & $2.7^{\mathrm{a}}$ & 15 & $2.1^{\mathrm{a}}$ & 21 & 2.1 \\
\hline Acarus siro & 20 & $11.6^{\mathrm{a}}$ & 10 & $9.1^{\mathrm{a}}$ & 71 & $9.7^{\mathrm{a}}$ & 101 & 10.0 \\
\hline Tyrophagus & 14 & $8.1^{\mathrm{a}}$ & 11 & $10.0^{\mathrm{a}}$ & 65 & $8.9^{a}$ & 90 & 8.9 \\
\hline Fleas & 12 & $7.0^{\mathrm{a}}$ & 6 & $5.5^{\mathrm{a}}$ & 48 & $6.6^{\mathrm{a}}$ & 66 & 6.5 \\
\hline Total & 172 & 100.0 & 110 & 100.0 & 729 & 100.0 & 1011 & 100.0 \\
\hline
\end{tabular}

Explanation: a - means marked with the same letter in columns do not differ significantly 
most common in the case of the other house dust mite, Dermatophagoides farinae $12.8 \%$ and $15 \%$, respectively. The allergen with the lowest frequency $(0.5 \%)$ were fungi of the genera Aspergillus and Penicillium. The allergens least often confirmed in the tests relative to the entire panel, were fungi of the genera Alternaria and Cladosporium and pollen from upright pellitory. Not a single dog tested in northern and central Poland had a positive reaction to any of these allergens.

The percentage of allergies to individual allergens varied by region (Tab. 4). Differences were observed in the case of Dermatophagoides pteronyssinus and Dermatophagoides farinae house dust mites, Acarus siro, and Tyrophagus. The remaining allergens caused allergic reactions in similar percentages of dogs from northern, central and southern Poland. The allergens of house dust mites Dermatophagoides pteronyssinus and Dermatophagoides farinae most often caused allergic reactions in dogs from northern and central Poland. The percentage of dogs from southern Poland allergic to this type of mite was significantly lower. A positive reaction to the Dermatophagoides farinae allergen was observed in more than $80 \%$ of dogs from the north and nearly $60 \%$ of dogs from central Poland, while in the south only $13 \%$ of dogs exhibited such a reaction. Similar relationships were observed for the mite Dermatophagoides pteronyssinus, with allergic reactions observed in $78 \%$ of dogs from northern Poland, nearly $60 \%$ of dogs from the central region, and about $13 \%$ of dogs from the south. The percentage of dogs from the
Tab. 4. Incidence of allergies to individual allergens in dogs in particular regions

\begin{tabular}{|c|c|c|c|c|c|c|c|c|c|}
\hline \multirow{2}{*}{ Allergen } & \multicolumn{3}{|c|}{ Northern Poland } & \multicolumn{3}{|c|}{ Central Poland } & \multicolumn{3}{|c|}{ Southern Poland } \\
\hline & 0 & 우 & Mean & $\hat{0}$ & 우 & Mean & $\hat{0}$ & q & Mean \\
\hline D. farinae & 78.6 & 84.6 & $81.6^{\mathrm{a}}$ & 66.7 & 52.9 & $59.8^{\mathrm{a}}$ & 13.5 & 12.3 & $12.9^{b}$ \\
\hline D. pteronyssinus & 71.4 & 84.6 & $78.0^{\mathrm{a}}$ & 66.7 & 47.1 & $56.9^{a}$ & 14.8 & 12.0 & $13.4^{b}$ \\
\hline Malassezia & 21.4 & 38.5 & $29.9^{a}$ & 8.3 & 23.5 & $15.9^{a}$ & 3.4 & 6.3 & $4.9^{\mathrm{a}}$ \\
\hline Lepidoglyphus & 42.9 & 53.8 & $48.4^{\mathrm{a}}$ & 25.0 & 17.6 & $21.3^{\mathrm{a}}$ & 7.4 & 8.6 & $8.0^{\circ}$ \\
\hline Aspergillus/Penicillium & 0.0 & 0.0 & $0.0^{\mathrm{a}}$ & 0.0 & 11.8 & $5.9^{\mathrm{a}}$ & 0.0 & 0.9 & $0.4^{\mathrm{a}}$ \\
\hline Alternaria/Cladosporium & 0.0 & 0.0 & $0.0^{\mathrm{a}}$ & 0.0 & 0.0 & $0.0^{\mathrm{a}}$ & 1.1 & 0.6 & $0.8^{\mathrm{a}}$ \\
\hline Ragweed & 7.1 & 15.4 & $11.3^{\mathrm{a}}$ & 0.0 & 17.6 & $8.8^{\mathrm{a}}$ & 1.8 & 2.3 & $2.1^{\mathrm{a}}$ \\
\hline Birch/Alder/Hazel & 42.9 & 38.5 & $40.7^{a}$ & 25.0 & 23.5 & $24.3^{\mathrm{a}}$ & 5.3 & 5.1 & $5.2^{\mathrm{a}}$ \\
\hline Plane tree/Willow/Poplar & 7.1 & 7.7 & $7.4^{\mathrm{a}}$ & 8.3 & 0.0 & $4.2^{\mathrm{a}}$ & 1.3 & 2.0 & $1.7^{\mathrm{a}}$ \\
\hline Parietaria & 0.0 & 0.0 & $0.0^{\mathrm{a}}$ & 0.0 & 0.0 & $0.0^{\mathrm{a}}$ & 0.5 & 1.4 & $1.0^{\mathrm{a}}$ \\
\hline Rye & 57.1 & 38.5 & $47.8^{\mathrm{a}}$ & 16.7 & 23.5 & $20.1^{\mathrm{a}}$ & 7.4 & 7.1 & $7.3^{\mathrm{a}}$ \\
\hline Mixed grasses & 42.9 & 30.8 & $36.8^{\mathrm{a}}$ & 8.3 & 23.5 & $15.9^{\mathrm{a}}$ & 5.5 & 5.7 & $5.6^{\mathrm{a}}$ \\
\hline Nettle & 7.1 & 7.7 & $7.4^{\mathrm{a}}$ & 0.0 & 17.6 & $8.8^{\mathrm{a}}$ & 1.1 & 1.7 & $1.4^{\mathrm{a}}$ \\
\hline Goosefoot & 14.3 & 7.7 & $11.0^{\mathrm{a}}$ & 0.0 & 11.8 & $5.9^{\mathrm{a}}$ & 1.3 & 1.7 & $1.5^{\mathrm{a}}$ \\
\hline Ribwort Plantain & 50.0 & 38.5 & $44.2^{\mathrm{a}}$ & 8.3 & 23.5 & $15.9^{\mathrm{a}}$ & 6.3 & 3.7 & $5.0^{\mathrm{a}}$ \\
\hline Mugworts & 7.1 & 15.4 & $11.3^{\mathrm{a}}$ & 0.0 & 11.8 & $5.9^{a}$ & 1.6 & 1.7 & $1.6^{\mathrm{a}}$ \\
\hline Sorrel & 14.3 & 7.7 & $11.0^{\mathrm{a}}$ & 0.0 & 17.6 & $8.8^{\mathrm{a}}$ & 1.8 & 2.3 & $2.1^{\mathrm{a}}$ \\
\hline Acarus siro & 78.6 & 69.2 & $73.9^{a}$ & 41.7 & 29.4 & $35.5^{\mathrm{ab}}$ & 10.3 & 9.1 & $9.7^{b}$ \\
\hline Tyrophagus & 50.0 & 53.8 & $51.9^{a}$ & 41.7 & 35.3 & $38.5^{\mathrm{a}}$ & 9.8 & 8.0 & $8.9^{b}$ \\
\hline Fleas & 57.1 & 30.8 & $44.0^{\mathrm{a}}$ & 8.3 & 29.4 & $18.9^{a}$ & 5.8 & 7.4 & $6.6^{\mathrm{a}}$ \\
\hline
\end{tabular}

Explanation: $\mathrm{a}, \mathrm{b}-$ means in columns marked with different letters differ significantly at $\mathrm{p} \leq 0.05$

Tab. 5. The results of allergy tests in dogs from northern Poland

\begin{tabular}{|c|c|c|c|c|c|c|c|c|c|c|}
\hline \multicolumn{11}{|c|}{ Northern Poland } \\
\hline \multirow{3}{*}{ Allergen } & \multicolumn{8}{|c|}{ Allergen class } & \multirow{3}{*}{ Total } & \multirow{3}{*}{$\begin{array}{l}\% \text { of } \\
\text { dogs }\end{array}$} \\
\hline & \multicolumn{2}{|c|}{0} & \multicolumn{2}{|c|}{1} & \multicolumn{2}{|c|}{2} & \multicolumn{2}{|c|}{$3-4$} & & \\
\hline & $\hat{0}$ & 우 & $\hat{0}$ & q & $\hat{0}$ & q & $\hat{0}$ & o & & \\
\hline D. farinae & 1 & 1 & 3 & 4 & 3 & 4 & 4 & 2 & 22 & 81 \\
\hline D. pteronyssinus & 4 & 5 & 1 & 5 & 5 & 1 & 0 & 0 & 21 & 78 \\
\hline Malassezia & 2 & 4 & 0 & 1 & 1 & 0 & 0 & 0 & 8 & 30 \\
\hline Lepidoglyphus & 1 & 4 & 0 & 2 & 5 & 1 & 0 & 0 & 13 & 48 \\
\hline Aspergillus/Penicillium & 0 & 0 & 0 & 0 & 0 & 0 & 0 & 0 & 0 & 0 \\
\hline Alternaria/Cladosporium & 0 & 0 & 0 & 0 & 0 & 0 & 0 & 0 & 0 & 0 \\
\hline Ragweed & 1 & 2 & 0 & 0 & 0 & 0 & 0 & 0 & 3 & 11 \\
\hline Birch/Alder/Hazel & 4 & 4 & 1 & 0 & 1 & 1 & 0 & 0 & 11 & 41 \\
\hline Plane tree/Willow/Poplar & 0 & 0 & 1 & 1 & 0 & 0 & 0 & 0 & 2 & 7 \\
\hline Parietaria & 0 & 0 & 0 & 0 & 0 & 0 & 0 & 0 & 0 & 0 \\
\hline Rye & 2 & 2 & 5 & 2 & 1 & 1 & 0 & 0 & 13 & 48 \\
\hline Mixed grasses & 1 & 2 & 3 & 1 & 2 & 1 & 0 & 0 & 10 & 37 \\
\hline Nettle & 0 & 0 & 1 & 1 & 0 & 0 & 0 & 0 & 2 & 7 \\
\hline Goosefoot & 1 & 0 & 1 & 1 & 0 & 0 & 0 & 0 & 3 & 11 \\
\hline Ribwort Plantain & 5 & 4 & 1 & 0 & 1 & 1 & 0 & 0 & 12 & 44 \\
\hline Mugworts & 1 & 2 & 0 & 0 & 0 & 0 & 0 & 0 & 3 & 11 \\
\hline Sorrel & 1 & 0 & 1 & 1 & 0 & 0 & 0 & 0 & 3 & 11 \\
\hline Acarus siro & 3 & 4 & 2 & 2 & 6 & 3 & 0 & 0 & 20 & 74 \\
\hline Tyrophagus & 1 & 3 & 1 & 2 & 4 & 2 & 1 & 0 & 14 & 52 \\
\hline Fleas & 8 & 3 & 0 & 1 & 0 & 0 & 0 & 0 & 12 & 44 \\
\hline Total & 36 & 40 & 21 & 24 & 29 & 15 & 5 & 2 & 172 & \\
\hline
\end{tabular}


north that were allergic to the flour mite Acarus siro $(73.9 \%)$ differed significantly from the percentage of allergic dogs in the south $(9.7 \%)$. No differences were found between central Poland and the other two regions. The reaction of dogs to Tyrophagus storage mites was similar to their reaction to house dust mites. The smallest percentage of dogs showing a reaction to this allergen was noted in southern Poland. In the northern and central regions, the percentage of dogs testing positive for Tyrophagus was statistically the same.

Table 5 presents the results of allergic tests of dogs from northern Poland (Gdańsk and vicinity) and the frequency of allergies to individual allergens among dogs from this part of the country. The factors that most contributed to the occurrence of allergies among dogs from northern Poland, i.e. Gdańsk and the surrounding area, were house dust mites Dermatophagoides farinae and Dermatophagoides pteronyssinus, to which 22 and 21 positive reactions, respectively, were found among 27 dogs tested. This means that $81 \%$ of animals in the study group were allergic to Dermatophagoides farinae, and $78 \%$ to Dermatophagoides pteronyssinus. Another relatively frequent allergenic factor was the mite Acarus siro (flour mite), which induced allergies in 20 individuals (74\%). The least common allergenic agents, diagnosed in two individuals each, were pollen from plane trees, willow and poplar and

Tab. 6. The results of allergy tests in dogs from central Poland

\begin{tabular}{|c|c|c|c|c|c|c|c|c|c|c|}
\hline \multicolumn{11}{|c|}{ Central Poland } \\
\hline \multirow{3}{*}{ Allergen } & \multicolumn{8}{|c|}{ Allergen class } & \multirow{3}{*}{ Total } & \multirow{3}{*}{$\begin{array}{l}\% \text { of } \\
\text { dogs }\end{array}$} \\
\hline & \multicolumn{2}{|c|}{0} & \multicolumn{2}{|c|}{1} & \multicolumn{2}{|c|}{2} & \multicolumn{2}{|c|}{$3-4$} & & \\
\hline & $\hat{\sigma}$ & q & $\sigma^{\lambda}$ & 우 & $\sigma^{\lambda}$ & q & $\hat{\sigma}$ & q & & \\
\hline D. farinae & 0 & 0 & 1 & 3 & 6 & 5 & 1 & 1 & 17 & 59 \\
\hline D. pteronyssinus & 5 & 1 & 1 & 5 & 2 & 2 & 0 & 0 & 16 & 55 \\
\hline Malassezia & 1 & 3 & 0 & 0 & 0 & 1 & 0 & 0 & 5 & 17 \\
\hline Lepidoglyphus & 2 & 0 & 0 & 3 & 1 & 0 & 0 & 0 & 6 & 21 \\
\hline Aspergillus/Penicillium & 0 & 1 & 0 & 0 & 0 & 1 & 0 & 0 & 2 & 7 \\
\hline Alternaria/Cladosporium & 0 & 0 & 0 & 0 & 0 & 0 & 0 & 0 & 0 & 0 \\
\hline Ragweed & 0 & 2 & 0 & 1 & 0 & 0 & 0 & 0 & 3 & 10 \\
\hline Birch/Alder/Hazel & 2 & 4 & 1 & 0 & 0 & 0 & 0 & 0 & 7 & 24 \\
\hline Plane tree/Willow/Poplar & 1 & 0 & 0 & 0 & 0 & 0 & 0 & 0 & 1 & 3 \\
\hline Parietaria & 0 & 0 & 0 & 0 & 0 & 0 & 0 & 0 & 0 & 0 \\
\hline Rye & 2 & 0 & 0 & 0 & 0 & 4 & 0 & 0 & 6 & 21 \\
\hline Mixed grasses & 0 & 0 & 1 & 0 & 0 & 4 & 0 & 0 & 5 & 17 \\
\hline Nettle & 0 & 2 & 0 & 1 & 0 & 0 & 0 & 0 & 3 & 10 \\
\hline Goosefoot & 0 & 2 & 0 & 0 & 0 & 0 & 0 & 0 & 2 & 7 \\
\hline Ribwort Plantain & 1 & 0 & 0 & 3 & 0 & 1 & 0 & 0 & 5 & 17 \\
\hline Mugworts & 0 & 2 & 0 & 0 & 0 & 0 & 0 & 0 & 2 & 7 \\
\hline Sorrel & 0 & 1 & 0 & 2 & 0 & 0 & 0 & 0 & 3 & 10 \\
\hline Acarus siro & 4 & 1 & 0 & 3 & 1 & 1 & 0 & 0 & 10 & 34 \\
\hline Tyrophagus & 3 & 3 & 1 & 3 & 1 & 0 & 0 & 0 & 11 & 38 \\
\hline Fleas & 1 & 4 & 0 & 0 & 0 & 1 & 0 & 0 & 6 & 21 \\
\hline Total & 22 & 26 & 5 & 24 & 11 & 20 & 1 & 1 & 110 & \\
\hline
\end{tabular}

pollen from nettle. Agents to which allergies were not detected in this group of animals were fungi of the genera Aspergillus and Penicillium and fungi of the genera Alternaria and Cladosporium, as well as pollen from Parietaria.

Among dogs from central Poland (Warsaw and vicinity), the most common factors causing allergies were house dust mites Dermatophagoides farinae and Dermatophagoides pteronyssinus, with 17 (59\%) and $16(55 \%)$ positive tests among 29 tested dogs. Allergens for which reactions were detected in dogs in this part of Poland with moderate frequency were flour mites Acarus siro, in 10 (34\%) individuals, and Tyrophagus mites, in 11 (38\%) individuals. Allergies to fungi of the genera Aspergillus and Penicillium, tree pollen (plane tree/willow/poplar), and pollen of goosefoot and mugwort were rare. Reactions to these allergens were detected in one or two individuals (up to $10 \%$ of the study population). No dog was found to be allergic to fungi of the genera Alternaria and Cladosporium or to pollen of Parietaria. The results of the allergy tests of dogs from central Poland (Warsaw and vicinity) and the frequency of allergies to specific allergens among dogs in this area are presented in detail in Table 6.

In dogs from southern Poland (around Kraków, Katowice and Nowy Sącz) allergies were most often caused by house dust mites Dermatophagoides farinae and Dermatophagoides pteronyssinus, with 94 and 98 positive reactions, respectively, among 129 dogs tested. This means that $73 \%$ of those dogs were allergic to Dermatophagoides farinae, and $76 \%$ to Dermatophagoides pteronyssinus. The second most important cause of allergies were mites Acarus siro and Tyrophagus, with positive results confirmed in $71(55 \%)$ and $65(50 \%)$ cases, respectively. Allergens that relatively frequently resulted in a positive reaction were storage mites (in 58 dogs) and rye pollen (in 53 dogs). Allergens that least frequently caused an allergic reaction were fungi of the genera Aspergillus and Penicillium (2\%), fungi of the genera Alternaria and Cladosporium, and pollen of Parietaria (5\%). Table 7 summarizes the results of allergy tests of dogs from southern 
Tab. 7. The results of allergy tests in dogs from southern Poland

\begin{tabular}{|c|c|c|c|c|c|c|c|c|c|c|}
\hline \multicolumn{11}{|c|}{ Southern Poland } \\
\hline \multirow{3}{*}{ Allergen } & \multicolumn{8}{|c|}{ Allergen class } & \multirow{3}{*}{ Total } & \multirow{3}{*}{$\begin{array}{l}\% 0 \\
\text { dogs }\end{array}$} \\
\hline & \multicolumn{2}{|c|}{0} & \multicolumn{2}{|c|}{1} & \multicolumn{2}{|c|}{2} & \multicolumn{2}{|c|}{$3-4$} & & \\
\hline & $\hat{0}$ & q & $\hat{0}$ & q & $\hat{0}$ & 우 & $\hat{0}$ & q & & \\
\hline D. farinae & 3 & 0 & 10 & 5 & 30 & 29 & 8 & 9 & 94 & 73 \\
\hline D. pteronyssinus & 23 & 12 & 19 & 12 & 14 & 17 & 0 & 1 & 98 & 76 \\
\hline Malassezia & 8 & 12 & 1 & 4 & 4 & 6 & 0 & 0 & 35 & 27 \\
\hline Lepidoglyphus & 12 & 15 & 13 & 6 & 3 & 9 & 0 & 0 & 58 & 45 \\
\hline Aspergillus/Penicillium & 0 & 2 & 0 & 1 & 0 & 0 & 0 & 0 & 3 & 2 \\
\hline Alternaria/Cladosporium & 4 & 2 & 0 & 0 & 0 & 0 & 0 & 0 & 6 & 5 \\
\hline Ragweed & 4 & 3 & 3 & 3 & 0 & 2 & 0 & 0 & 15 & 12 \\
\hline Birch/Alder/Hazel & 15 & 12 & 4 & 1 & 1 & 5 & 0 & 0 & 38 & 29 \\
\hline Plane tree/Willow/Poplar & 3 & 2 & 1 & 1 & 1 & 4 & 0 & 0 & 12 & 9 \\
\hline Parietaria & 0 & 2 & 0 & 1 & 2 & 2 & 0 & 0 & 7 & 5 \\
\hline Rye & 15 & 12 & 4 & 4 & 9 & 4 & 0 & 5 & 53 & 41 \\
\hline Mixed grasses & 11 & 9 & 2 & 3 & 8 & 3 & 0 & 5 & 41 & 32 \\
\hline Nettle & 3 & 1 & 0 & 3 & 1 & 2 & 0 & 0 & 10 & 8 \\
\hline Goosefoot & 3 & 0 & 1 & 2 & 1 & 4 & 0 & 0 & 11 & 9 \\
\hline Ribwort Plantain & 14 & 7 & 6 & 1 & 4 & 4 & 0 & 1 & 37 & 29 \\
\hline Mugworts & 4 & 1 & 2 & 4 & 0 & 1 & 0 & 0 & 12 & 9 \\
\hline Sorrel & 1 & 2 & 5 & 1 & 1 & 4 & 0 & 1 & 15 & 12 \\
\hline Acarus siro & 13 & 7 & 13 & 12 & 13 & 13 & 0 & 0 & 71 & 55 \\
\hline Tyrophagus & 13 & 6 & 12 & 10 & 12 & 11 & 0 & 1 & 65 & 50 \\
\hline Fleas & 18 & 19 & 4 & 5 & 0 & 1 & 0 & 1 & 48 & 37 \\
\hline Total & 167 & 126 & 100 & 79 & 104 & 121 & 8 & 24 & 729 & \\
\hline
\end{tabular}

Allergens for which the IgE concentration reached class 3-4 were the least common, accounting for $4.1 \%$ of allergic reactions. Classes 1 and 2 accounted for $25.0 \%$ and $29.7 \%$ of the total, respectively, which indicates a moderate frequency of allergic reactions in these classes. Class 0 allergic reactions were noted in the largest number of cases, accounting for $41.2 \%$ of the total (Fig. 2, Tab. 8).

The statistical analysis showed that the distribution of the number of allergic reactions among classes was similar in the three regions. In class 0 , a positive result was obtained in $44.2 \%$ of subjects from northern Poland, $43.6 \%$ from central Poland, and $40.2 \%$ from southern Poland. In class 1 , the percentage of individuals with a positive result ranged from $24.6 \%$ (in southern Poland) to 29\% (in central Poland). Similar percentages of allergic reactions were observed for class 2 (from $25.6 \%$ in northern Poland to $30.6 \%$ in southern Poland). Allergens with a class $4 \operatorname{IgE}$ concentration were the least common, with about $4 \%$ in each region. In addition, the number
Poland and the frequency of allergies to individual allergens among animals from this region.

Figure 2 presents the incidence of each class of allergic reactions without taking into account the region, while Table 8 presents the incidence of these classes in individual regions of the country.

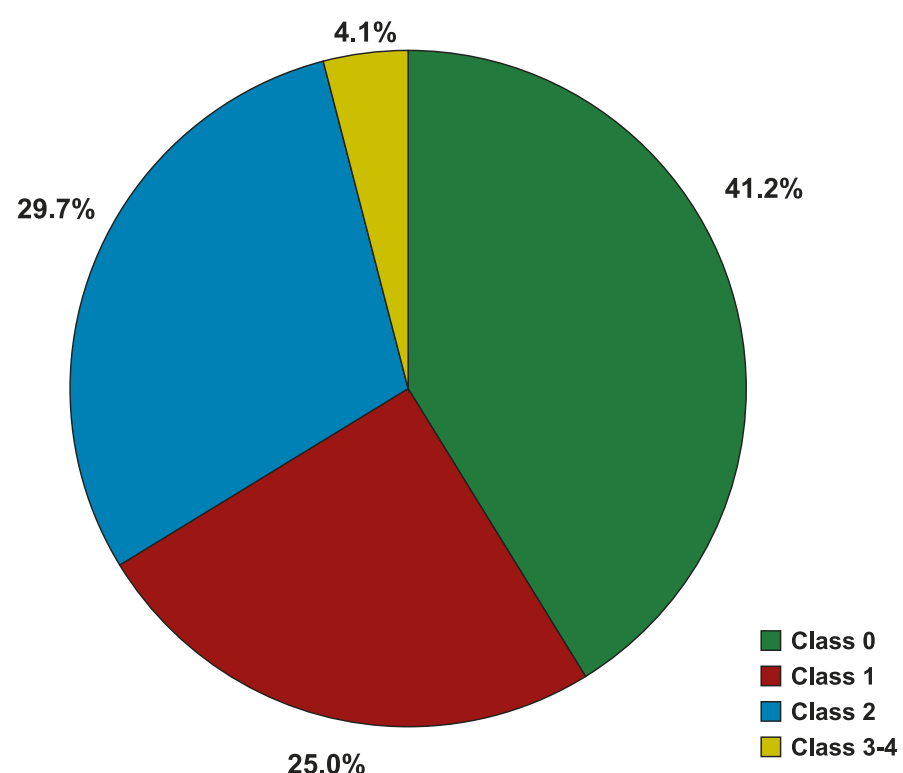

Fig. 2. Percentage share of allergic reactions in each class of positive results in particular classes was shown to differ significantly in females from different regions. No such differences were found in males. Allergic reactions caused by class 0 and 1 allergens were least common in females from southern Poland $(17.3 \%$ and $10.8 \%$ ), class 2 allergies were least common in northern Poland (8.7\%), and those caused by group 3 allergens in central Poland $(0.9 \%)$.

Irrespective of the region, allergens of classes 0 and 3-4 induced a similar percentage of positive reactions in both sexes. Differences between sexes and regions were observed in the case of allergens with concentrations of class 1 and 2 . In the case of allergens with class 1 concentrations, the greatest differences in incidence were found for males $(4.5 \%)$ and females $(21.8 \%)$ from central Poland. Class 2 allergens were much more likely to cause allergic reactions in males from northern Poland and females from central Poland.

Allergies in dogs have become a relatively frequent topic of discussion in veterinary surgeries. Many dogs, purebred or of mixed breeds, are diagnosed for allergies. Allergies have many causes, from genetic predisposition to environmental conditions in which the animal lives.

Hakanen et al. (8) confirm that the occurrence of allergic reactions in a dog is influenced by the envi- 
Tab. 8. Frequency of each class of allergic reactions in animals tested and the chi-square test $\left(\chi^{2}\right)$ value

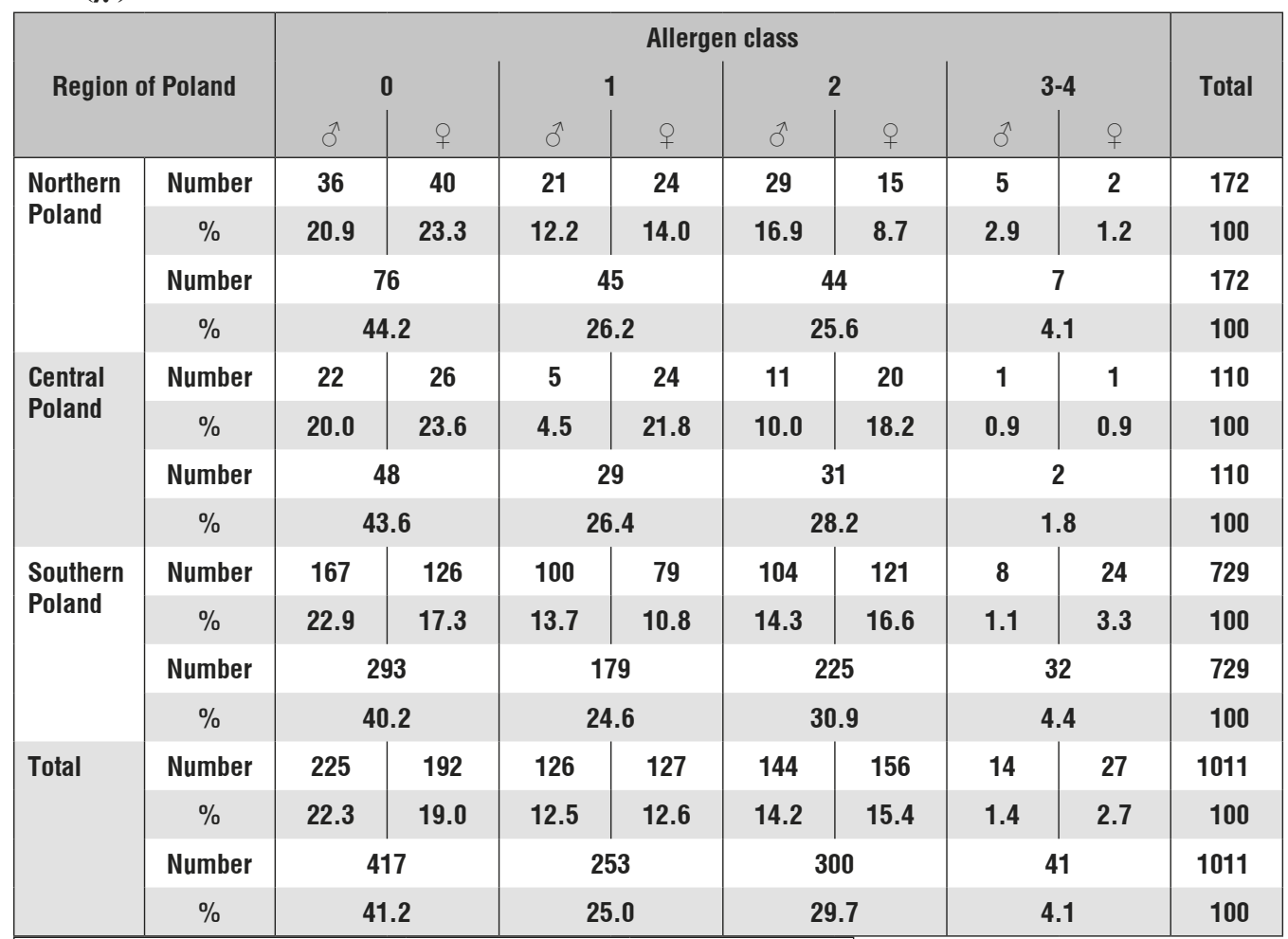

\begin{tabular}{|l|c|c|}
\hline Chi square test $\left(\chi^{2}\right)$ value: & \\
For allergen class & 3.90 & $\mathrm{p}=0.69$ \\
For males in allergen classes & 8.08 & $\mathrm{p}=0.23$ \\
\hline For females in allergen classes & $17.25^{*}$ & $\mathrm{p}=0.00$ \\
\hline For sex in class 0 & 3.69 & $\mathrm{p}=0.16$ \\
\hline For sex in class 1 & $15.10^{*}$ & $\mathrm{p}=0.00$ \\
\hline For sex in class 2 & $7.88^{*}$ & $\mathrm{p}=0.02$ \\
\hline For sex in class 3-4 & 5.74 & $\mathrm{p}=0.06$ \\
\hline
\end{tabular}

Explanation: * significant at $\mathrm{p} \leq 0.05$

ronment where the animal lives. Rural areas are less exposed to all types of air pollution, which the authors confirmed in their research. That study showed that dogs living in the countryside are less susceptible to allergies. Animals raised in these areas also have more contact with various naturally occurring microorganisms, which enhances their immunity from their first days of life. More allergic dogs were noted in urban areas, where the air quality is much worse. In addition, these animals spend most of their lives indoors, having much less contact with microorganisms outside, which significantly limits their acquisition of adequate immunity. The study confirmed that dogs living in rural areas in Finland, Sweden and Switzerland were significantly less predisposed to atopic dermatitis. The research carried out in the present study also confirms this relationship. Patients of veterinary clinics are most often dogs that have owners and live in houses or flats. This explains the very high percentage of allergies caused by mites, especially house dust mites.

A study by Lehtimaki et al. (12) confirmed that environment and lifestyle have a major influence on the frequency of allergies in dogs. The authors also found a difference in the composition of skin flora between dogs living in the city and in the countryside. The study demonstrated that active contact with the environment has an enormous impact on a dog's immunity and reduces the incidence of allergies. This is also supported by the results of our research.

Research results given in the literature confirm that the most common allergies include reactions to environmental allergens. In our study carried out in Poland, the majority of diagnosed allergies were also environmental (contact) allergies, mainly to mites. In reference to studies by Cork (5), Marsella et al. (15) and Niemand (18), according to which the skin is the fastest route of allergen absorption, it can be confirmed that allergens that enter the dog's body in this way are the most commonly encountered and diagnosed. Penetration of allergens is facilitated by disturbances in the structure of the epidermis, and for this reason allergies occur more often in animals kept in large cities. The skin of these dogs is more susceptible because of the far inferior quality of the environment.

Comparison of the results of our research supports the theory that dogs raised in a more polluted environment, in this case in southern Poland, are more prone to allergies. There was also a noticeable difference in the number of patients tested and cases with positive allergy test results between southern Poland and northern or central Poland. Significantly fewer dogs were tested for allergies in northern Poland than in southern Poland. Southern Poland is well known to be more urbanized than northern Poland, so air pollution in the south of the country is much greater than in the north. In addition, Gdańsk is very close to the Baltic Sea, which considerably improves its air quality. Therefore, the large difference in the number of allergy patients between the south and north of Poland may be due to the difference in the levels of environmental pollution contributing to the occurrence of allergies.

To reduce the risk of allergies in a dog, it is important to ensure that it has a healthy lifestyle and an appropriate environment, including contact with other animals, which will have a positive impact on the dog's overall health. 
Bjelland et al. (1) studied the frequency and risk factors of an increased $\mathrm{IgE}$ concentration for specific allergens in the Norwegian dog population. The study showed that the most common allergens were house dust mites Dermatophagoides farinae and flour mites Acarus siro. Allergens in flea saliva, on the other hand, were very rarely detected, as there is a relatively small flea population in Scandinavia. This study confirms that Poland is not the only country where dog owners are struggling with their pets' hypersensitivity to mites. This problem may result from the relatively high level of pollution in the animals' environment. In the present study as well, fleas were not the dominant source of allergens.

The study by Bjelland et al. (1) also showed that females were more susceptible to allergens penetrating the skin. This was confirmed by our study in Poland. Both Norwegian and Polish dogs were more often diagnosed with indoor allergens than with those occurring outdoors.

Another thesis supported by Bjelland et al. (1) was that older dogs are more susceptible to allergic reactions. In our research this thesis could not be confirmed because of the lack of data regarding the age of the dogs tested.

The research presented by Bjelland et al. (1) shows the influence of geographic location on the occurrence of allergies in dogs. This is linked to rainfall and humidity, which are not conducive to the development of mites. Northern Norway is less humid and has lower annual rainfall, which explains the higher rate of positive allergic reactions in dogs in this part of the country. There are a great many factors influencing the occurrence of allergies in dogs. Most studies, however, confirm that it is the environment that is the main determinant of tendencies for allergic reactions in dogs. The main allergens that cause concern to animal owners, in Poland and other countries, are dust mites. Therefore, it is important for a dog to have contact with various animals from the earliest moments of its life and to be kept in a suitable environment that will strengthen its immune system, thereby reducing the tendency for allergic reactions.

Despite the increasing awareness of the importance of allergic diseases in animals, the discipline of veterinary allergology lags behind its human counterpart. There are several reasons for this. The full methodology available in human allergology often cannot be transferred to other species without modification, such as the development of a simple ELISA assay to detect monoclonal antibodies specific for the species of interest. However, for dogs, cats and horses, some of these reagents are already available. In recent years, increasing efforts have led to the creation of new reagents and technologies and have stimulated research in the field of veterinary allergology, resulting in the identification of new allergens and a deeper understanding of the specific pathogenesis of allergic diseases in animals. The availability of diagnostic methods, together with increased awareness of allergic diseases in veterinary practice and in the general population of pet owners, has facilitated the development of diagnostics of allergic diseases. Veterinary allergology has become an important dedicated veterinary discipline, and allergic disorders in man's best friend are slowly gaining the attention they deserve, not only as models of human allergies.

\section{References}

1. Bjelland A. A., Dolva F. L., Nødtvedt A., Scevik B. K.: Prevalence of and risk factors for increased serum levels of allergen-specific $\mathrm{IgE}$ in a population of Norwegian dogs. Acta Vet. Scand. 2014, 56, 81, doi.org/10.1186/s13028-0140081-z 1-11.

2.Boer D. J. de, Hillier A.: The ACVD task force on canine atopic dermatitis (XV): fundamental concepts in clinical diagnosis. Vet. Immunol. Immunopathol. 2001, 81, 271-276.

3. Boralevi F., Hubicke T., Leante-Labrze C., Sanbusse E., Fayon M., Roul S. Epicutaneous aeroallergen sensitization in atopic dermatitis infants - determining the role of epidermal barrier impairment. Allergy 2008, 63, 205-210.

4. Brazis P., Serra M., Selles A., Dethioux F., Biourge V., Puigdemont A.: Evaluation of storage mite contamination of commercial dry dog food. Vet. Dermatol. 2008, 19, 209-214.

5. Cork M. J., Danby S. G., Vasilopoulos Y., Hadgraft J., Lane M. E., Moustafa M., Guy R. H., Macgowan A. L., Tazi-Ahnini R., Ward S. J.: Epidermal barrier dysfunction in atopic dermatitis. J. Invest. Darmatol. 2009, 129, 1890-1908.

6. Farmaki R., Saridomichelakis M. N., Leontides L., Papazahariadou M. G., Gioulekas D., Koutinas A. F.: Dust mite species in the households of mitesensitive dogs with atopic dermatitis. Vet. Dermatol. 2012, 23, 222-e45, doi: 10.1111/j.1365-3164.2012.01052.x

7.Hakanen E., Lehtimaki J., Salmela E., Tiira K., Anturaniemi J., HielmBjörkman A., Ruokolainen L., Lohi H.: Urban environtment predisposes dogs and their owners to allergic symptoms. Sci. Rep. 2018, 8, 1585, doi:10.1038/ s41598-018-19953-3.

8. Hallwell R.: Revised nomenclature for veterinary allergy. Vet. Immunol. Immunopathol. 2006, 114, 207-208.

9. Hardy J. I., Hendricks A., Loeffler A., Chang Y. M., Verheyen K. L., Garden $O$. A., Bond R.: Food-specific serum IgE and IgG reactivity in dogs with and without skin disease: lack of correlation between laboratories. Vet. Dermatol. 2014, 25, 447-470.

10. Ichikawa Y., Beugnet F.: Epidemiological survey of anti-flea IgE in dogs in Japan by using an antigen-specific IgE quantitative measurement method. Parasite 2012, 19, 173-176

11. Jackson A. P., Foster A. P., Hart B. J., Helps C. R., Shaw S. E.: Prevalence of house dust mites and dermatophagoides group 1 antigens collected from bedding, skin and hair coat of dogs in south-west England. Vet. Dermatol. 2005, 16, 32-38

12.Lehtimäki J., Sinkko H., Hielm-Björkman A., Salmela E., Tiira K., Laatikainen T., Mäkeläinen S., Kaukonen M., Uusitalo L., Hanski I., Lohi H., Ruokolainen L.: Skin microbiota and allergic symptoms associate with exposure to environmental microbes. Proc. Natl. Acad. Sci. USA 2018, 115, 4897-4902.

13. Marsella R., Girolomoni G.: Canine models of atopic dermatitis: a useful tool with untapped potential. J. Invest. Dermatol. 2009, 129, 2351-2357.

14. Marsella R., Saridomichelakis M. N.: Environmental and oral challenge with storage mites in beagles experimentally sensitized to Dermatophagoides farinae. Vet. Dermatol. 2010, 21, 105-111.

15. Marsella R., Sousa C. A., Gonazales A. J., Fadok V. A.: Current understanding of the pathophysiologic mechanisms of canine atopic dermatitis. J. Am. Vet. Med. Assoc. 2012, 241, 194-207.

16. Martin A., Paz Sierra M., Gonzales J., Angelles A. M.: Identification of allergens responsible for canine cutaneous adverse food reactions to lamb, beef and cow's milk. Vet. Dermatol. 2004, 15, 349-356.

17. Mueller R. S., Janda J., Jensen-Jarolim E., Rhyner C., Marti E.: Allergens in veterinary medicine. Allergy 2015, 71, 27-35.

18. Niemand H. G.: Praktyka kliniczna: psy. Wydawnictwo Galaktyka, Łódź 2015.

19. Olivry T., DeBoer D. J., Favrot C., Jackson H. A., Mueller R. S., Nuttall T., Prélaud P.: Treatment of canine atopic dermatitis: 2010 clinical practice guidelines from the International Task Force on Canine Atopic Dermatitis. Vet. Dermatol. 2010, 21, 233-248. 
20. Roussel A. J., Bruet V., Bourdeau P. J.: Characterisation of dog sensitisation to grass pollen in western France from 1999 to 2010. Vet. Rec. 2013, 172, 686, doi: 10.1136/vr.100710.

21. Schamber P., Schwab-Richards R., Bauer-Sachs S., Mueller R. S.: Gene expression in the skin of dogs sensitized to the house dust mite Dermatophagoides farinae. G3: Genes - Genomes - Genetics 2014, 4, 1787-1795.

22. Szczepanik M., Adamek ., Wilkołek P.: Diagnostyka atopowego zapalenia skóry u psów oraz ocena obrazu klinicznego choroby. Życie Wet. 2010, 85, 332-337.

23. Szczepanik M., Śmiech A., Zadrzyńska K., Wilkotek P.: Kontaktowe zapalenie skóry u psów i kotów - przyczyny, rozpoznanie i leczenie. Życie Wet. 2010, $85,921-924$
24. Szczepanik M., Wilkołek P.: Rola zaburzeń bariery skórnej w atopowym zapaleniu skóry u psów. Życie Wet. 2012, 87, 672-674.

25. SzczepanikM., Wilkotek P., Chmielecka K.:Alergia pokarmowa u psów i kotów. Magazyn Wet. 2014, 23, 20-24

26. Verlinden A., Hesta M., Millet S., Janssens G. P.: Food allergy in dogs and cats. Crit. Rev. Food Sci. Nutr. 2006, 46, 259-273.

27. Zur G., Ihrke P. J., White S. D., Kass P. H.: Canine atopic dermatitis: a retrospective study of 266 cases examined at the University of California, Davis, 1992-1998. Part I. Clinical features and allergy testing results. Vet. Dermatol. 2002, 13, 89-102.

Corresponding author: Mgr inż. Bartosz Jania, ul. B. Prusa 14, 08-110 Siedlce, Poland; e-mail: bartosz.jania@uph.edu.pl 